\title{
Changes in the Properties of an Asphalt During the Blowing Operation
}

\author{
L. R. Kleinschmidt and H. R. Snoke
}

\begin{abstract}
The physical characteristics and component distribution of an asphalt flux and of asphalt products taken at six two-hour intervals during the conversion, by air blowing, of the flux to a coating-grade asphalt, were determined. The softening point and asphaltene content of the asphalt products increased linearly with time during the blowing operation There was essentially no change in percentage, refractive index, and viscosity of the waterwhite oils during blowing. The percentage and refractive index of the dark oils decreased progressively during the blowing operation.
\end{abstract}

\section{Introduction}

The National Bureau of Standards, in cooperation with the Asphalt Roofing Industry Bureau, is engaged in the study of the constitution of asphalt and the mechanism of degradation of asphalt on weathering. A method has been published for the chromatographic separation of asphalt into groups of components [1]. ${ }^{1}$

Asphalt fluxes are the residues from refinery processes that remove the lower-boiling fractions from petroleum. Asphalts used in the manufacture of roofings are made by blowing air through the fluxes at elevated temperatures. Normally, the softening point of the asphalt products is increased and the ductility and penetration decreased by blowing for longer periods of time.

As part of the study of the constitution and degradation of asphalt, it seemed desirable to determine the effect of the blowing process on the physical characteristics and component distribution of an asphalt to correlate any changes, if possible, with the mechanism of degradation.

\section{Experimental Procedure}

\subsection{Materials and Methods}

A 50-ton charge of a typical asphalt flux was blown at $375^{\circ}$ to $400^{\circ} \mathrm{F}$ for a period of $11^{3 / 4} \mathrm{hr}$, at the rate of $500 \mathrm{ft}^{3}$ of air per minute. The laboratory examinations were carried out within 1 month after the blowing operation. The differences in the physical characteristics of the original flux and of the asphalt products removed at 2 -hr intervals and the differences in the distribution and physical characteristics of similar components in these products were determined.

The following methods of the American Society for Testing Materials were used in determining the chemical and physical characteristics of the asphalt flux, asphalt products, and their components:

Figures in brackets indicate the literature references at the end of this paper:

Softening point
Penetration $\begin{aligned} & \text { D36-26 } \\ & \text { Ductility } \ldots \ldots\end{aligned}$

Refractive indices of the oily constituents were determined with an Abbe-type refractometer for the wavelength of the sodium D line.

\subsection{Separation Into Components}

The asphalt components separated were those described in reference [1], namely, asphaltenes, asphaltic resins, water-white oils, and dark oils. Because the chromatographic method described in [1] did not provide specimens large enough for further work, the following method was substituted:

\section{a. Asphaltenes}

One hundred and fifty grams of the asphalt products were digested in 6 liters of $n$-pentane for $18 \mathrm{hr}$. The $n$-pentane was contained in a glass cylinder, $15 \mathrm{~cm}$ in diameter and $45 \mathrm{~cm}$ high, and the asphalt sample was suspended in a wire basket just under the surface of the $n$-pentane. The difference between the specific gravity of the asphalt (approximately 1) and the $n$-pentane (0.63) set up convection currents which facilitated greatly the extraction of the $n$-pentane soluble components. At the end of the digestion period the insoluble matter in the basket was transferred to a 2-liter beaker and digested with 1 liter of $n$-pentane for $1 \mathrm{hr}$, then transferred to a Buchner funnel and washed with $n$-pentane until the washings were light straw in color. This insoluble matter, designated as asphaltenes, was air-dried until free from the odor of $n$-pentane, heated at $212^{\circ} \mathrm{F}$ for $1 \mathrm{hr}$, cooled, and weighed.

\section{b. Total Oily Constituents}

The volume of the filtrate from the $n$-pentane insoluble was adjusted to contain approximately $45 \mathrm{ml}$ of $n$-pentane for each gram of asphalt processed. To this solution 100- to 200-mesh fuller's earth was added, with rapid stirring, until the color 
of the solution changed from a blackish-brown to a light yellowish-green. The more viscous (longer blown) asphalts required from 1 to $1 \frac{1 / 2}{\mathrm{~g}}$ of fuller's earth for each gram of asphalt processed. This procedure has several advantages over that of Strieter [2] who used a fixed ratio ${ }^{2}$ of fuller's earth to asphalt. It establishes a control for the quantity of fuller's earth; it gives a more definite separation between the groups of components, and it reduces greatly subsequent extraction operations.

The fuller's earth was recovered by filtration, using a Buchner funnel, transferred to extraction thimbles, and extracted in Soxhlet extractors for $10 \mathrm{hr}$ with $n$-pentane, using a 6 -min cycling rate. The filtrate and washings from the fuller's earth were combined with the Soxhlet extractions and the $n$-pentane was evaporated. The nonvolatile residue has been designated the total oily constituents.

\section{c. Asphaltic Resins}

The fuller's earth from the determination of total oily constituents was air dried and extracted with ethyl ether in Soxhlet extractors until the washings were colorless. The nonvolatile residue from the extract constituted the asphaltic resins.

\section{d. Fractionation of Total Oily Constituents}

The total oily constituents were fractionated into water-white and dark oils by a modification of the procedure described in reference [1], as follows:

\section{e. Water-White Oils}

A 15-g sample of the total oily constituents, dissolved in approximately $100 \mathrm{ml}$ of $n$-pentane, was placed in a column containing $225 \mathrm{~g}$ of fuller's earth and eluted as described in [1]. The nonvolatile residue from the eluate has been designated water-white oils.

\section{f. Dark Oils}

The components adsorbed by the fuller's earth during the elution of the water-white oils were recovered by eluting with $50 \mathrm{ml}$ of chloroform, followed by methyl ethyl ketone. The nonvolatile residue from this eluate has been designated dark oils.

\section{Results}

\subsection{Physical Characteristics}

The softening points, ductilities, and penetrations of the asphalt products taken at 2-hr intervals during the blowing operation are shown graphically in figures 1 to 3 , inclusive. During the blowing operation the softening point increased linearly with time. Practically all of the change in ductility of the asphalt products occurred during the first $6 \mathrm{hr}$ of blowing (fig. 2). Practically all of the change in penetration occurred during the first $8 \mathrm{hr}$ of blowing (fig. 3).

\footnotetext{
${ }^{2}$ Five grams of fuller's earth to $1 \mathrm{~g}$ of asphalt.
}

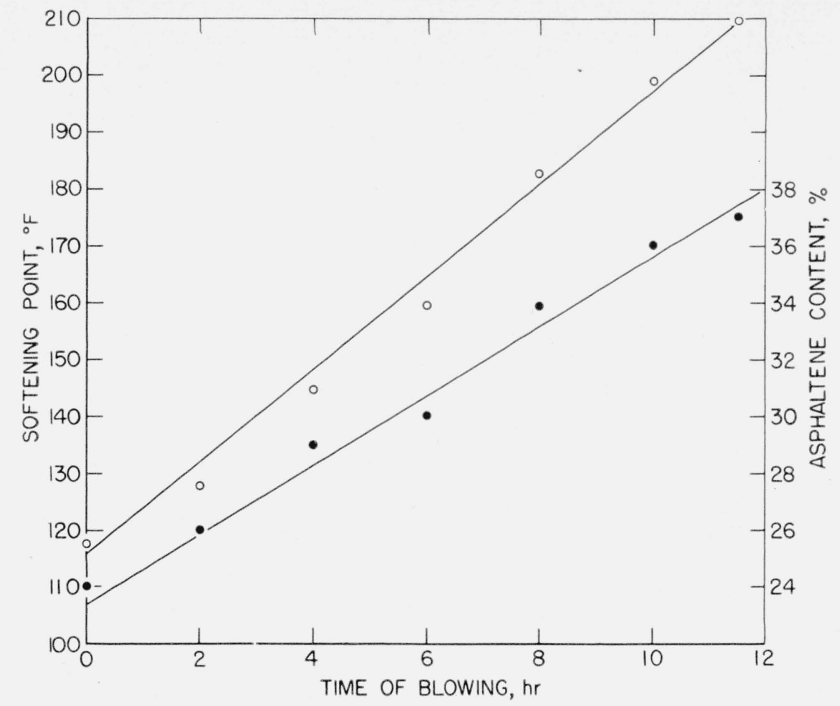

FIGURE 1. Softening point and percentage asphaltenes of asphalt products.

$\boldsymbol{O}$, Softening point; $\boldsymbol{O}$, percent asphaltenes.

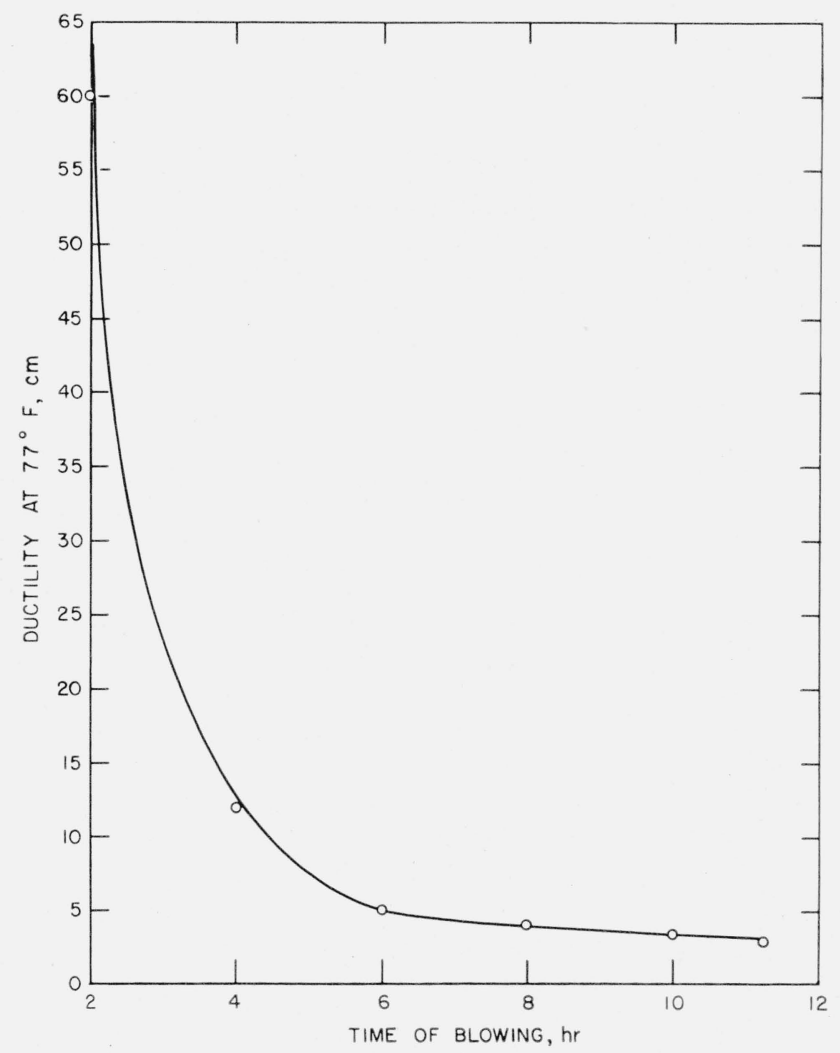

FIGURE 2. Ductility of asphalt products. 


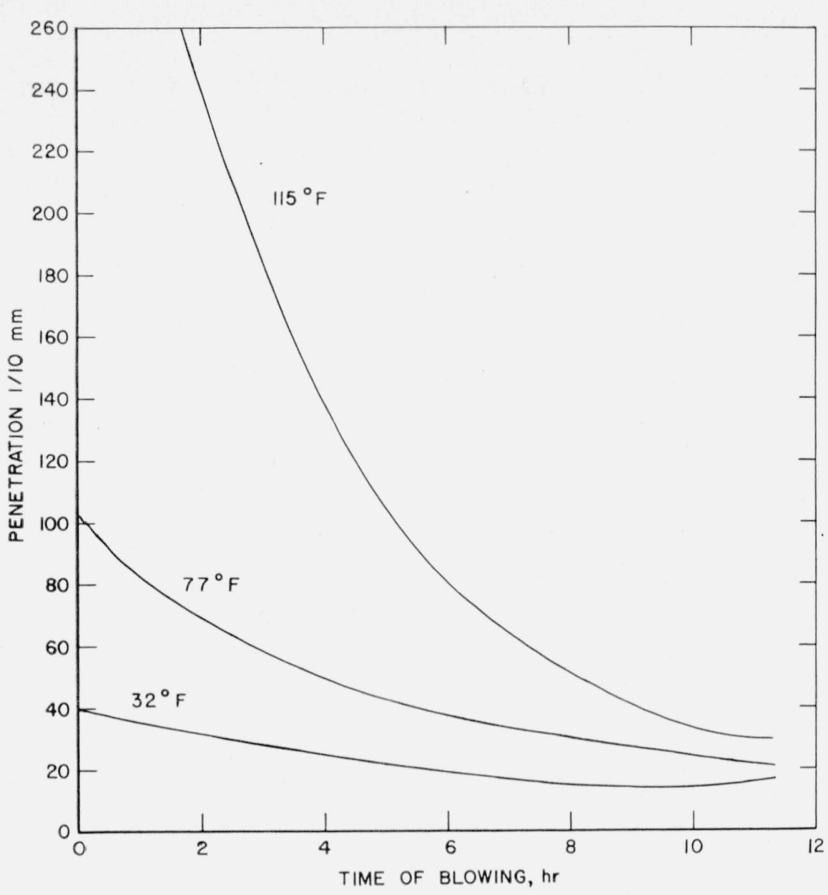

Figure 3. Penetration of asphalt products.

\subsection{Component Distribution}

The percentages of asphaltenes, asphaltic resins, and total oily constituents in the original flux and in the asphalt products are shown in table 1 . The percentages of oily constituents and asphaltic resins

TABLE 1.-Component distribution in asphalt products

\begin{tabular}{|c|c|c|c|c|c|c|c|}
\hline Time of blowing ......... $\mathrm{hr}$ & 0 & 2 & 4 & 6 & 8 & 10 & $11^{3 / 4}$ \\
\hline \multicolumn{8}{|l|}{ Components: } \\
\hline Asphaltenes & 24 & 26 & 29 & 30 & 34 & 36 & 37 \\
\hline Asphaltic resins ...... & 17 & 15 & 14 & 14 & 13 & 13 & 13 \\
\hline $\begin{array}{l}\text { Total oily constitu- } \\
\text { ents }\end{array}$ & 58 & 58 & 56 & 56 & 53 & 51 & 49 \\
\hline Total recovery & 99 & 99 & 99 & 100 & 100 & 100 & 99 \\
\hline
\end{tabular}

decreased as blowing proceeded, while the percentage of asphaltenes recovered increased linearly with the time of blowing as shown in figure 1 .

The percentage of asphaltic resins decreased 2 percent during the first $2 \mathrm{hrs}$ of blowing and only 2 percent during the remainder of the blowing operation. The precision of the asphaltic resin determination is \pm 0.5 percent.

In table 2 are reported the percentages and some physical characteristics of the total oily constituents, water-white oils, and dark oils, recovered from the flux and the asphalt products. Changes that occurred in the percentages of the total oily constituents resulted primarily from changes of the dark oil components. 'These decreased from 32 to 24 percent during the blowing period. The following significant differences in the physical characteristics of the total oily constituents from the different products were observed: the refractive index decreased from 1.513 to 1.505 and the viscosity from 448 to 305 centistokes. The percentages, refractive indices, and viscosities of the water-white oils remained essentially constant during the blowing operation.

TABLE 2.-Characteristics of oily constituents

\begin{tabular}{|c|c|c|c|c|c|c|c|}
\hline Time of blowing .......... & 0 & 2 & 4 & 6 & 8 & 10 & $11^{3 / 4}$ \\
\hline $\begin{array}{l}\text { Total oily constituents_. } \% \text {-- } \\
\text { Refractive index at } 100^{\circ} \mathrm{F}- \\
\text { Viscosity at } 140^{\circ} \mathrm{F}\end{array}$ & $\begin{array}{r}58 \\
1.513 \\
448\end{array}$ & $\begin{array}{r}58 \\
\text { 1. } 512 \\
438\end{array}$ & $\begin{array}{r}56 \\
\text { 1. } 511 \\
372\end{array}$ & $\begin{array}{r}56 \\
\text { 1. } 511 \\
409\end{array}$ & $\begin{array}{r}53 \\
1.507 \\
302\end{array}$ & $\begin{array}{r}51 \\
1.507 \\
298\end{array}$ & $\begin{array}{r}49 \\
1.505 \\
305\end{array}$ \\
\hline $\begin{array}{l}\text { Water-white oils: } \\
\text { Percentage a } \\
\text { Refractive index at } 100^{\circ} \mathrm{F}- \\
\text { Viscosity at } 140^{\circ} \mathrm{F}\end{array}$ & $\begin{array}{r}24 \\
\text { 1. } 488 \\
109\end{array}$ & $\begin{array}{r}26 \\
\text { 1. } 487 \\
109\end{array}$ & $\begin{array}{r}26 \\
1.488 \\
110\end{array}$ & $\begin{array}{r}26 \\
\text { 1. } 488 \\
110\end{array}$ & $\begin{array}{r}28 \\
1.487 \\
112\end{array}$ & $\begin{array}{r}26 \\
1.487 \\
\quad 111\end{array}$ & $\begin{array}{r}25 \\
\text { 1. } 488 \\
109\end{array}$ \\
\hline $\begin{array}{l}\text { Dark oils: } \\
\text { Percentage a } \\
\text { Refractive index at } 100^{\circ} \mathrm{F}\end{array}$ & $\begin{array}{r}32 \\
1.543\end{array}$ & $\begin{array}{r}31 \\
\text { 1. } 540\end{array}$ & $\begin{array}{r}29 \\
\text { 1. } 538\end{array}$ & $\begin{array}{r}30 \\
\text { 1. } 540\end{array}$ & $\begin{array}{r}25 \\
1.543\end{array}$ & $\begin{array}{r}24 \\
\text { 1. } 536\end{array}$ & $\begin{array}{r}24 \\
1.536\end{array}$ \\
\hline
\end{tabular}

a Calculated on asphalt products.

\subsection{Coke Residue}

In table 3 are reported the coke residues determined on asphalt products, asphaltenes, and several of the total oily constituents and asphaltic resins. The percentage of coke residue of the asphaltenes, of the asphaltic resins, and of the total oily constituents differed greatly. Although the conversion of the flux into an asphalt product having a softening point of $210^{\circ} \mathrm{F}$ increased the asphaltenes 24 to 37 percent, the coke residue of the asphaltenes remained essentially the same. If the increase in the asphaltenes was due to an adsorption of the maltenes, ${ }^{3}$ marked changes occurred in the structure of the adsorbed maltenes. Physical adsorption alone would have resulted in a progressively lower coke residue of the asphaltenes as blowing progressed.

The percentages of coke residue in the asphalt products increased progressively during the blowing operation and approximately linearly with the asphaltene content of the asphalt products as shown in figure 4 .

TABLE 3. Coke residue of asphalt products and components

\begin{tabular}{|c|c|c|c|c|c|}
\hline \multirow{3}{*}{$\begin{array}{l}\text { Time } \\
\text { of } \\
\text { blow- } \\
\text { ing }\end{array}$} & \multicolumn{5}{|c|}{ Coke residue } \\
\hline & \multirow{2}{*}{$\begin{array}{c}\text { Asphal- } \\
\text { tenes }\end{array}$} & \multirow{2}{*}{$\begin{array}{c}\text { Asphal- } \\
\text { tic } \\
\text { resins }\end{array}$} & \multirow{2}{*}{$\begin{array}{c}\text { Total } \\
\text { oily con- } \\
\text { stituents }\end{array}$} & \multicolumn{2}{|c|}{ Asphalt products } \\
\hline & & & & $\begin{array}{l}\text { Deter- } \\
\text { mined }\end{array}$ & $\begin{array}{l}\text { Calcu- } \\
\text { lated }\end{array}$ \\
\hline Hours & $\%$ & $\%$ & $\%$ & $\%$ & $\%$ \\
\hline 0 & 39.5 & 12. 2 & 0.8 & 12.0 & 12.0 \\
\hline 2 & 38.5 & - n- & -...- & 12.5 & - n- \\
\hline 4 & 37.1 & ---- & --- & 12. 9 & 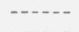 \\
\hline $\begin{array}{l}0 \\
8\end{array}$ & $\begin{array}{l}38.4 \\
37.6\end{array}$ & 11.3 & 0.3 & $\begin{array}{l}13.4 \\
14.4\end{array}$ & 14.3 \\
\hline 10 & 37.4 & & & 15.0 & \\
\hline $113 / 4$ & 38.2 & 12.4 & 0.5 & 15.9 & 16.1 \\
\hline
\end{tabular}

${ }^{3}$ The $n$-pentane soluble constituents of asphalt. 


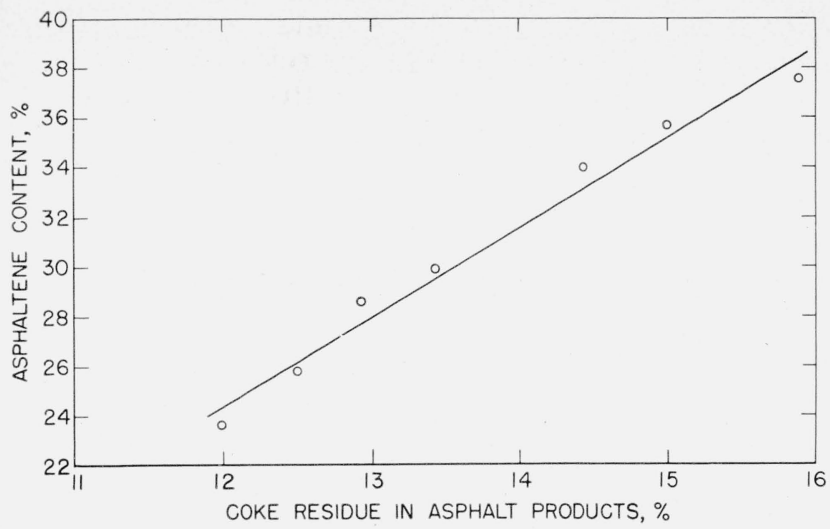

FIGURE 4. Relationship between asphaltene formation and coke residue.

\subsection{Iodine Value and Sulfur Content}

In table 4 are reported the iodine values and the percentages of sulfur determined in the flux and in the asphalt product blown $11^{3 / 4} \mathrm{hr}$. Also reported in this table are similar determinations made on the asphaltenes, asphaltic resins, and water-white and dark oils derived from these products. The slight differences in the iodine value, between the flux and the blown product and of the components separated from these two materials showed that no marked changes occurred in the halogen reactivity of the flux during blowing.

The sulfur content of the flux and of the asphalt produet blown $11 \frac{3}{4} \mathrm{hr}$ were the same $(2.0 \%)$, showing that no sulfur was lost during the blowing operation. The differences in the sulfur content of the asphaltenes, asphaltic resins, water-white oils, and dark oils determined in the flux and the product blown $11 \frac{3}{4} \mathrm{hr}$ were of such small magnitude that it was apparent the sulfur content could not be used to determine changes in components during the blowing operation.

TABLE 4. Iodine value and percentage sulfur-flux and asphalt product blown $11^{3 / 4}$ hours

\begin{tabular}{|c|c|c|c|c|}
\hline \multirow{2}{*}{ Material } & \multicolumn{2}{|c|}{ Iodine value a } & \multicolumn{2}{|c|}{ Sulfur } \\
\hline & $\begin{array}{l}\text { Asphalt } \\
\text { flux }\end{array}$ & $\begin{array}{l}11^{3} / 4 \mathrm{hr} \\
\text { asphalt } \\
\text { product }\end{array}$ & $\begin{array}{l}\text { Asphalt } \\
\text { flux }\end{array}$ & $\begin{array}{l}11^{3} / 4 \mathrm{hr} \\
\text { asphalt } \\
\text { product }\end{array}$ \\
\hline $\begin{array}{l}\text { Asphalt } \\
\text { Asphaltenes. } \\
\text { Asphaltic resins } \\
\text { Water-white oils } \\
\text { Dark oils }\end{array}$ & $\begin{array}{l}40 \\
51 \\
48 \\
10 \\
42\end{array}$ & $\begin{array}{r}41 \\
53 \\
45 \\
8 \\
39\end{array}$ & $\begin{array}{l}\% \\
2.0 \\
3.0 \\
2.4 \\
0.2 \\
2.4\end{array}$ & $\begin{array}{l}\% \\
2.0 \\
3.8 \\
2.3 \\
0.2 \\
2.3\end{array}$ \\
\hline
\end{tabular}

a Centigrams of iodine combining with $1 \mathrm{~g}$ of material.

\section{Summary}

During the conversion of a 50-ton charge of asphalt flux to produce asphalt products with properties suitable for use in roofing, samples were taken at 2 -hr intervals during the blowing operation which was carried out at $375^{\circ}$ to $400^{\circ} \mathrm{F}$ for $11^{3 / 4} \mathrm{hr}$. The distribution of the components in the flux and in the asphalt products and the properties of the flux, products and components were determined as part of a study of the constitution and degradation of asphalt.

The softening point of the asphalt products increased linearly from $118^{\circ}$ to $210^{\circ} \mathrm{F}$ during the blowing operation. The penetration and ductility decreased rapidly during the first $6 \mathrm{hr}$ of blowing and relatively little thereafter.

The asphaltene content of the asphalt products increased linearly with the time of blowing. The percentage of coke residue from the asphaltenes of the different products remained essentially constant, indicating that polymerization occurred in the adsorbed maltenes. The mechanism by which the asphaltenes were formed was not established. No changes were found in the percentage or physical characteristics of the water-white oils in samples taken during the blowing operation.

The close agreement between the iodine values of the asphait flux and the final blown product indicated no marked change in halogen reactivity during the blowing operations.

The authors are indebted to George W. Clarvoe, Asphalt Research, Johns-Manville Corporation, who furnished the specimens for this investigation.

\section{References}

[1] L. R. Kleinschmidt, J. Research NBS 54, 163, (1955) RP2577.

[2] O. G. Strieter, J. Research NBS 26, 415, (1941) RP1387.

Washington, September 10, 1957 